\title{
Participatory Ethnomedicinal Cancer Research with Fante-Akan Herbalists in Rural Ghana
}

Summer Ragosta ${ }^{1^{*}}$, Ivelyn Harris ${ }^{2}$, Ntim Gyakari ${ }^{3}$, Emmanuel Otoo ${ }^{4}$, and Alex Asase ${ }^{5}$

Author Addresses: ${ }^{1}$ Surfing Medicine International, P.O. Box 548, Waialua, Hawaii 96791, USA. ${ }^{2}$ Rio Grande Valley Jamaica Maroons, Moore Town, Portland, Jamaica. ${ }^{3}$ Freelance Botanist and Technical Herbalist, P.O. Box 1457, Kumasi, Ghana. ${ }^{4}$ P.O. Box SP116, Salt Pond, Ghana. ${ }^{5}$ Botany Department, University of Ghana at Legon, P.O. Box LG 55, Legon, Ghana.

*Corresponding author: surfingmedicine@gmail.com

Received: September 23, 2014

Volume: $6(1): 66-79$

Published: July 21, 2015

(C) 2015 Society of Ethnobiology

Abstract: An ethnomedicinal study was initiated with herbalists in coastal Central Region Ghana to explore how cancer is defined, diagnosed, and treated within a traditional Fante-Akan context. The participatory, service-oriented investigation included international collaboration with herbalists and traditional plant experts. On-site meetings informed community leaders and members of project intent and methods, guided protocol, and gauged critical support. To provide immediate educational and economic opportunities, hands-on activities with villagers transferred academic and applied skills. Ethnographic interviews and voucher specimen collections were conducted with seven herbalists. Plant samples were dried and housed locally in a community herbarium cabinet constructed in Kormantse. Ten cancer ethnopharmacopoeia plants were identified, most of which are species considered native to tropical Africa. Fante Akan herbalists listed various types of cancers they treat with herbal remedies, along with ethnomedicinal descriptions of disease etiology, diagnoses, and treatments. The most common cancer type mentioned was "breast cancer." Topical application was the most often cited method of administering remedies. Researchers established key contacts in the Kormantse, Salt Pond, and Elmina communities, and identified local and international research collaborators for a proposed interdisciplinary project focused on longitudinal case studies with herbalists, patients, and medical physicians.

Keywords: Ethnomedicine, Ghana, Collaborative research, Ethnopharmacopoeia, Cancer

Background

Herbal medicine is a primary healthcare option for people in the developing world (Cunningham 1993). In Africa, for instance, people often consult community herbalists in matters of disease and well-being. Previous studies in rural Central Ghana suggest that the decision to use traditional medicine (herbalists or spiritual healers), as opposed to biomedicine (conventional or "Western medicine"), is affected by several factors including access, affordability, as well as cultural views of disease, wellness, and traditional healing methods (Aikins 2005; Hill et al. 2003). For example, research investigating herbal malaria treatments in Fante regions of Central Ghana (Mankessim and Kasoa) showed that people select herbal remedies even when pharmaceutical remedies are readily available, due to their lower cost per dose (Asase and Oppong-Mensah 2009). Furthermore, differences in traditional and biomedical terminology (particularly in the area of nosology), appear to present a barrier to integrative treatments (healthcare that encourages or uses both traditional and biomedi- cal approaches) (Hill et al. 2003).

The principal area of study is Kormantse, a coastal village in the Central Region of Ghana, West Africa, located approximately 62 miles west of the capital city Accra. Fante Akan dialect dominates in Kormantse, a historically important fishing and farming community that played a prominent role in the slave trade. The primary occupation is fishing; however, mining activities also occur in the region. ${ }^{1}$ Kormantse borders Salt Pond to the east and Abandze to the west, and has a population of about 6,500 people (personal communications with Nana Kwame Akyen II, Adontenhen of Mankessim Traditional Area and Chief of Kormantse). Kormantse owns a basic school where its members seek their education, and has one medical clinic that treats minor illness and provides injury first aid. The nearest hospital is Saltpond Municipal Hospital, about a 25 minute drive by car. Herbal medicines are commonly used by Kormantse residents due to their affordability and familiarity as compared to pharmaceutical drugs. 
According to Laryea et al. (2014), region-specific cancer rates have not been adequately documented in Ghana. The first population-based cancer registry in the country was established in 2012 in the urban city of Kumasi, located in the Ashanti Region about 110 miles north of Kormantse. The Kumasi registry data showed that the most commonly diagnosed cancers were, in decreasing order, liver, prostate, lung, and stomach among men; and breast, cervix, ovary, and endometrium among women (Laryea et al. 2014). Country-wide data from 2012 indicated that cervical cancer is the most commonly diagnosed cancer among Ghanaian women (American Cancer Society 2015), with over $50 \%$ of these cases attributed to the vaccine preventable ${ }^{2}$ human papillomavirus (HPV) types 16 and 18 (Ebu et al. 2015). According to Adanu et al. (2010), regular cervical cancer screening (associated with early detection and improved mortality rates for women diagnosed with the disease) is not common in Ghana. An ethnographic study of cervical cancer awareness among Fante women in Elmina (a large coastal town about 22 miles west of Kormantse) identified social (e.g., religious and cultural beliefs), institutional (e.g., no local screening clinics, lack of health education and cervical cancer information), and cost factors that prevented women from seeking cervical cancer screening tests (Ebu et al. 2015). These barriers to conventional biomedical access are juxtaposed by relatively high numbers of traditional medicine practitioners in Ghana (compared to number of physicians), leading many to choose herbal medicine in matters of disease treatment and prevention (Busia 2005).

\section{Ethnomedicinal Comparisons}

Since traditional herbal medicine is a critical component of rural healthcare, safety and efficacy are a concern for both herbalists and the public they serve, and many traditional practitioners in Africa have expressed interest in cooperating with biomedical physicians to improve their status as respected healthcare providers (Busia 2005). However, in order to make cross-cultural parallels between traditional and conventional medicine, ethnomedicinal terminology must first be relatable to biomedical taxonomy. Yet, there are currently no studies known to us that adequately describe and define Fante ethnomedicinal taxonomy in a conventional medicine context.

Social constructs of wellness and remedy efficacy vary within and across ethnicities, and some health related expressions may be wholly culturally con- structed (Etkin 1988; Kleinman 1978). Associating emic disease terms with ethnographically derived descriptions of etiology, treatment procedures, and biological symptoms and systems can improve understandings of ethnomedicinal concepts which, when correlated with biomedical classification systems, may facilitate comparative research and cross -cultural collaborations, improve health education programs, as well as increase access to and overall quality of healthcare (Berlin and Berlin 2005; Browner et al. 2007; Etkin 1988).

Through collaborative and participatory ethnobotanical research, our goal is to better understand traditional remedies for cancer and to facilitate crosscultural medical knowledge transfer. Although no perfect protection from unintended and unforeseen misappropriation of published information is known to the authors, this ethnomedicinal documentation aims to protect intellectual property of participating Fante herbalists by presenting prior art evidence pertaining to traditional knowledge of bioactivity associated with the plant species listed here, ${ }^{3}$ with the intention of discouraging its use in extra-cultural and non-collaborative ventures. ${ }^{4}$ Furthermore, it is anticipated to augment positive safeguards legislated in intellectual property rights laws, acts, and instruments administered by the Ghana Registrar-General's Department (Dutfield 2003; Sackey and Kasilo 2010). Our publication objective is to provide Fante Akan herbalists in Kormantse and surrounding areas access to their traditional knowledge in a written format, and to encourage grassroots-initiated collaborative ethnomedicinal projects focused on sustainable equitable economic and social development in the region. Two primary questions guide this research: 1) What plant species are used in Fante Akan cancer ethnopharmacopoeia; and 2) How is cancer defined, diagnosed, and treated within the traditional herbalist practitioner system in coastal areas of Central Region Ghana?

\section{Methods}

This study initiation was conducted under ethical guidelines proposed by the 2006 International Society of Ethnobiology (2006) Code of Ethics (with 2008 additions). Prior informed consent documents were drafted according to University of Ghana Noguchi Medical Research Institutional Review Board guidelines. Previous exploratory research carried out in

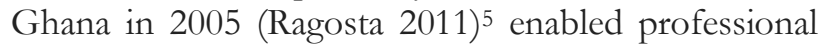
relationships and rapport to develop among investiga- 
tors and community participants. Over a period of several months (September 2012 to July 2013), project discussions by mail, email, and telephone allowed Ghanaian co-researchers and key collaborators to review methodology, ask questions, and suggest changes. The preliminary field study was conducted over a period of ten days in July and August 2013. Additional follow-up meetings and plant collections with participating herbalists and local project leaders (carried out in July 2014 and April 2015) confirmed interview data and species identifications.

We worked with traditional herbalists who use plants to heal and treat disease. Selection of herbalist participants was purposive and accomplished with help from local key collaborators ${ }^{6}$ (Bernard 2006; Tongco 2007). A village meeting was initiated to gauge support, identify participants, and review research methods with community members and leaders. Individual written informed consent was received prior to each interview. A Fante-English translator assisted in prior informed consent discussions and interviews. Research goals, including intention to publish results of the study, and data collection methodology were discussed in detail with each individual participant. Potential risks associated with unintended misappropriation of published information were described to participants by means of prior informed consent documentation and discussions. Herbalists were asked to not disclose information they wished to remain secret. Participants were given opportunity to review the article manuscript and were asked for final permission prior to publication.

Data gathering methods included plant collections and formal semi-structured interviews using predetermined open-ended and direct questions (Bernard 2006); for example, "What conditions do you treat?," "Please explain the effects of the remedies you use to treat cancer", "What plants are in your remedies?," and "Can you show us the plant(s) and may we take a sample?"

Most of the herbalists were interviewed initially in group settings, followed by individual interviews and observations at each participant's place of practice. ${ }^{7}$ Group interviews and nightly plant pressing activities functioned as training sessions for community members leading herbarium management, participant meeting organization, and subsequent interviews and plant collections.

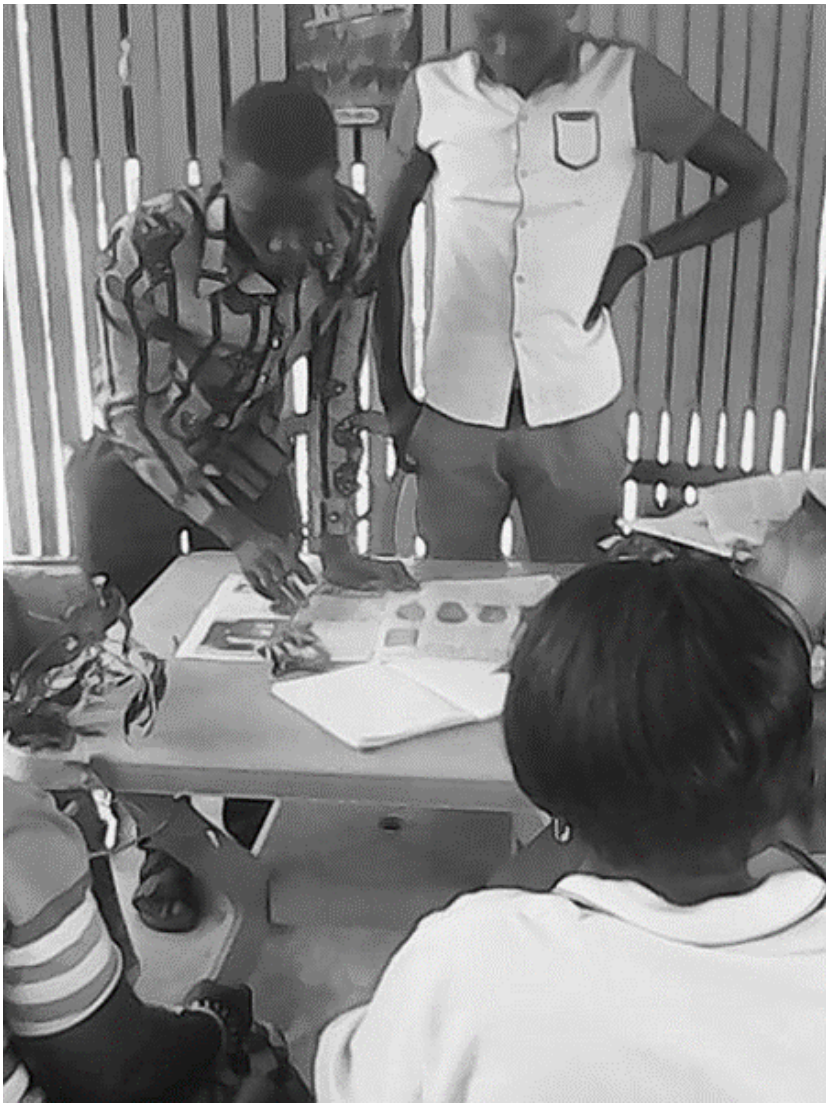

Figure 1. Collecting voucher specimens for the Kormantse Herbarium.

Pressed and dried plant samples (voucher specimens) were prepared to provide a concrete link between vernacular and botanical classification systems and to positively identify species discussed and shown to researchers during interviews (Alexiades and Sheldon 1996; Etkin et al. 1999). Specimens were pressed and dried in the village of Kormantse (Figure 1). After foreign researchers left Ghana, participating community members mounted the dried vouchers and constructed a small herbarium cabinet to house the specimens. The Kormantse participants also sent a set of vouchers for deposit in the National Forestry Commission Herbarium in Kumasi.

A Ghanaian taxonomist (Gyakari) worked with researchers to assist with plant identification in the field. Dichotomous keys published in the Flora of Tropical West Africa (Hutchinson and Dalziel 1936, 1954, 1958, 1963, 1968, 1972) were consulted to aid species determinations. Digital photographs were taken of plant specimens to create a virtual copy of the herbarium. Plant taxonomy and authorship was authenticated with TROPICOS (Missouri Botanical 


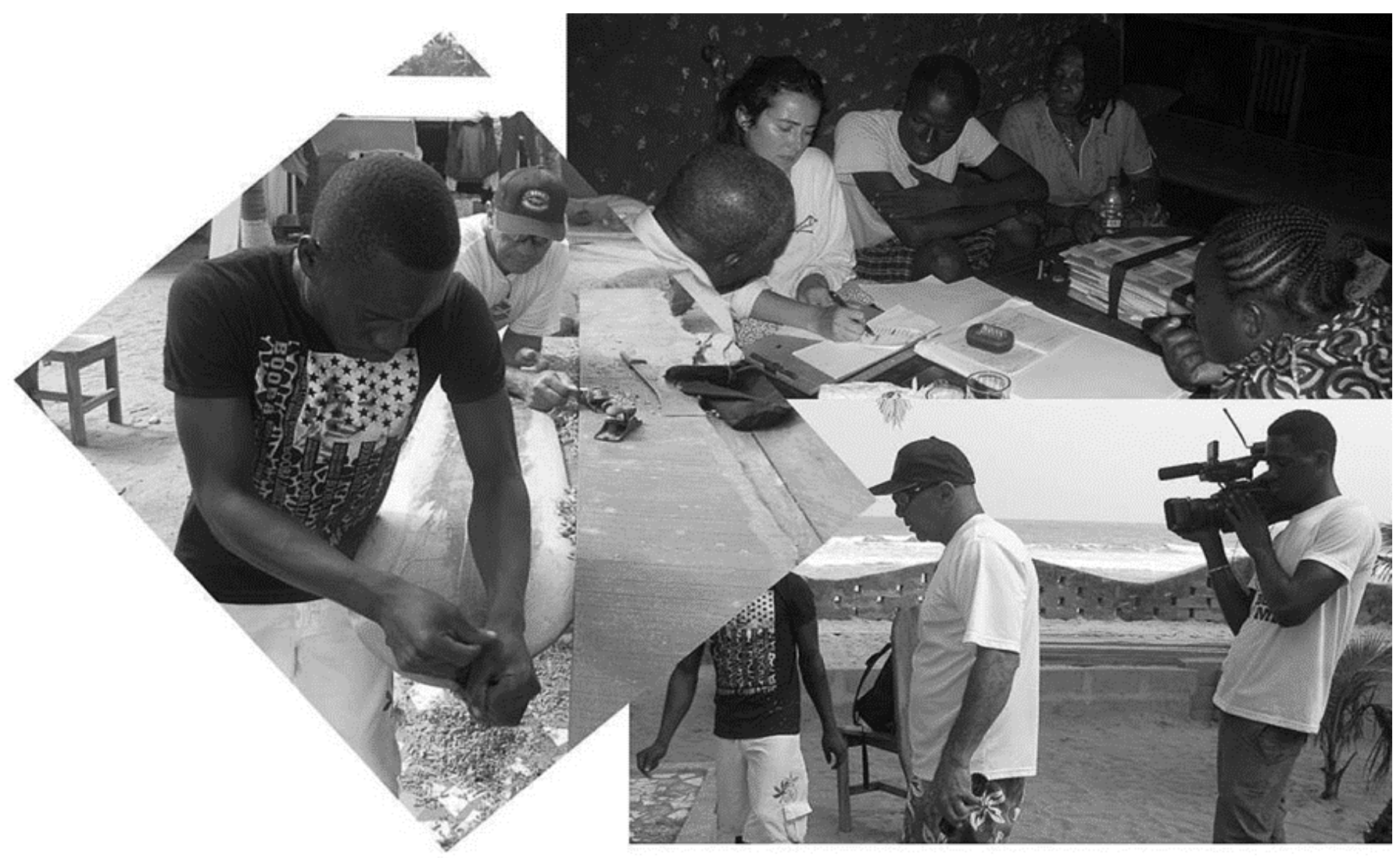

Figure 2. Local participants receive hands-on training in both practical and academic arts; clockwise from left to right: handcarved wooden craft, voucher preparation and taxonomy, and videography. Photos by Guy A. Ragosta.

Garden 2014) and The Plant List (2013) databases. Distribution status was verified via African Plant Database (2012) and the Flora of Tropical West Africa (Hutchinson and Dalziel 1936, 1954, 1958, 1963, 1968, 1972).

We focused on building long-term relationships in the community through educational service projects and participatory research (Juliá and Kondrat 2005; Kobetz et al. 2009; Vandebroek 2013). Crosscultural experiential educational sessions were organized and led by experts from Jamaica, Ghana, and the United States. ${ }^{8}$ Community participants were given opportunities to learn through hands-on activities and small-group sessions (ranging from about two to seven participants) focusing on videography, ethnography, medicinal plant taxonomy and use, African Diaspora ethnohistory, voucher curation, native timber species seed germination, and handcarved craft (Figure 2). These activities were filmed by both foreign project leaders and Kormantse community members. To fully involve the community in all aspects of the research, from the planning and methods development stages to the research write-up and publication submission process, correspondence was maintained between foreign and local project leaders and herbalists via mail, email, phone, and text. Official project meetings with participating herbalists and local leaders were held in Kormantse after foreign researchers left Ghana, and drafts of the preliminary research summary and results were shared with meeting attendees for review and approval.

\section{Results}

As a result of this project, the participating herbalists residing in the Kormantse and Salt Pond areas have established a Fante herbalist consortium, which acts as a steering committee for long-term research goals and local project development. A major focus for the herbalists is to construct a centralized clinic as a place to consult with and treat patients, as well as to collaboratively research aspects of their ethnomedicinal knowledge.

Interviews, collections, and observations were carried out with seven Fante herbalists, including five 
Table 1. Fante herbalist cancer ethnopharmacopoeia.

\begin{tabular}{llll}
\hline Family & Species & Local name & Species distribution \\
\hline Apocyanceae & Voacanga africana Stapf & Amadansowaa & Tropical Africa \\
Apocynaceae & Rauvolfia vomitoria Afzel. & Kakapempem; & Tropical Africa \\
Asteraceae & Aspilia africana (P. Beauv. ex Pers.) C.D. Adams & Mfofo & Tropical Africa \\
Euphorbiaceae & Tragia sp. L. & Nsason; ensasonno & N/A \\
Fabaceae & Dialium guineense Willd. & Oserene & Tropical Africa \\
Fabaceae & Mimosa pigra L. & Asisirow & Pan-tropical \\
Lamiaceae & Hoslundia opposita Vahl & Abrewanyikanfo & Tropical and South Africa \\
Marantaceae & Marantochloa conferta (Benth.) A. C.Ley & Not recorded & Tropical Africa \\
Nyctaginaceae & Boerhavia diffusa L. & Ntradaa & Pan-tropical \\
Sapindaceae & Paullinia pinnata L. & Toantini; & Pan-tropical
\end{tabular}

men and two women. We identified ten cancer ethnopharmacopoeia species used by these herbalists (Table 1). The herbalists talked about "different kinds of cancer" they have treated with plant based remedies: breast, leg, hand, arm, head, nose, penis, prostate, skin, stomach, thigh, abdomen tumor, and vagina. Breast cancer was the most commonly cited cancer type treated (mentioned by five out of seven herbalists). One herbalist emphasized that there are various types of breast cancer.

None of the herbalists reported any adverse side effects related to their herbal medicine treatments. One herbalist who claimed to have successfully treated about 100 people for cancer stated that "for every cancer there is a particular herb that is appliedfor different cancers-leg, hand, breast, etc.... and for every herb there is a manner of approaching the herb."

Cancer was described by one herbalist as a "chronic sore." Another herbalist expounded on the definition, saying, "Outside sores can develop into inside sores, an early stage of cancer." To further explain, this herbalist told us,

With leg and arm cancers you will see boils. An outside boil is an indication of an inside sore, and when you press on it the person will feel pain. In the breast there will be no boil, [instead] you will feel a hard painful lump inside and [the person] will feel pain around the heart. Because there are a lot of veins in the breast, stones will form inside, meaning that there is an inside wound or sores. Also one of the symptoms is itchiness.

Researchers observed pulverized plant material used in topical treatment applications. One herbalist explained that for both leg and breast cancers the same medicine is used. First, an ointment is applied; then, pulverized woody plant material (a combination of three different plants) is put into a broad leaf and applied to the patient, left for nine days, then replaced. This and other cancer treatment preparation and administration methods mentioned and observed during interviews are presented in Table 2. ${ }^{\circ}$ Of the recorded methods, topically applied remedies were the most common. Often, multiple plant species are used in combination. For example, one herbalist who claimed to have cured eight people from breast cancer described one remedy as a combination of four different herbs; the fresh leaves are ground together and rubbed on the patient. Or, if the plant material is dry, it will be pounded first, and then ground into a powder, which can be applied directly to the patient or made into a paste first by adding a little water. The herbalist went on to say that the same herbs can also be dried and boiled to make a tea for internal consumption. Another herbalist who had been working collaboratively with other herbalists for over 40 years 
(f) Ethnobiolocy Letters research Communication

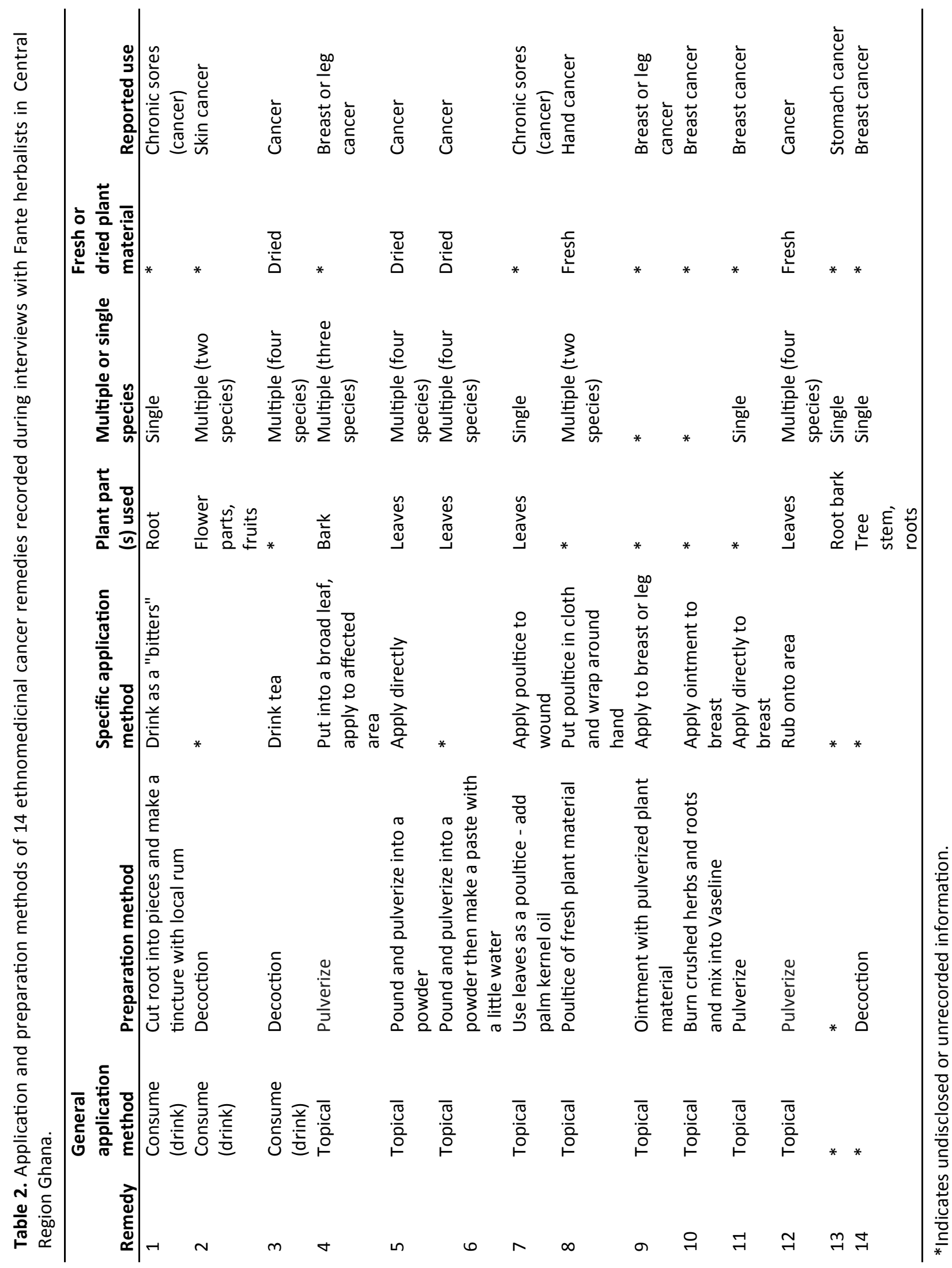

Ethnobiology Letters. 2015. 6(1): 66-79. DOI: 10.14237/ebl.6.1.2015.253. 
showed us a dried and pulverized mixture of three plant species used in breast cancer treatments.

Most of the herbalists stated they diagnose cancer through observation of the patient and "looking at the symptoms." One herbalist explained,

There are different kinds of cancer.

Each cancer has its own dosage-

breast, leg, hand, vagina. I look at the symptoms then diagnose based on past experience. Then I can say what type of cancer, and then prescribe a particular herb for it. And different people with the same cancer may even get a different herb.

Another herbalist said, "I look at the symptoms [for leg, breast, and thigh cancers]. Different parts of the body indicate symptoms." Other diagnostic measures mentioned included patient and medical doctor feedback. For example, according to one herbalist, "Doctors confirm diagnosis and cure." Another indicated that they look at the symptoms and ask the patient about physical symptoms.

Responses to questions regarding duration of cancer treatment regimens ranged from one week to several months. For example, one herbalist stated that "early stage" cancer can be treated in one to two weeks, or up to one month. Another herbalist also talked about cancer "stages," explaining that the duration of treatment depends on factors such as age of the patient, secondary illnesses the patient may have, and "the stage of sickness. Initial stage is treated in one week, second stage treated in two weeks, worst stage treated in two-three months." Similarly, a different herbalist described treatments in relation to the "stage" of cancer. When asked about treatment efficacy, this herbalist said,

Within one hour time of applying herbs, pain vanishes. Then after continued treatment the boil vanishes. Then with continued treatment, the patient will still feel pain, and then the sores heal. Early stage cancer can be treated in one week. Worst stage cancer takes three months.

Other patient health determinants described by herbalists included observations, feedback, and physician confirmations. For example, one herbalist had a dwelling place for the patients so they could be monitored and observed for signs of wellness. This person recalled an instance when a man from the village came to the herbalist's home. He could not walk, so the herbalist concluded that he had cancer. After applying herbal treatments for three months, the man improved and began to walk. Another herbalist listed a three-step process to decide if a patient is healed: "(1) observation, (2) patient testimony, (3) try a two week period of no treatment to check if sickness comes back or not." This same herbalist also explained,

When patients are brought in I look at the symptoms and diagnose, take photographs of them, then start treatment-apply medicine; look at the stages [over time], up or down, then compare the first picture to the last picture and draw conclusions based on changes in observations.

Two other herbalists stated that patients confirm with medical doctors that their cancer has been cured. One herbalist described the physical symptoms of a cure,

For every cancer there is a "sore" inside-so to know if it is cured, you touch the skin and the patient will not feel pain at all; but if they do feel pain (or burning), then there is still a sore inside.

One herbalist stated that cancer can be caused by exposure to harmful substances ("chemicals") in food, or in lotions that are absorbed through the skin. For example, the herbalist explained,

Some lotions cause bleaching of the skin, which will remove a layer of the skin and can cause cancer. Other lotions have chemicals that will attack the breast and decompose the breast. Also, women in Africa store money in their bras and chemicals from the coins are hazardous to the breast.

The herbalist further explained that cancer can be caused by physical injury to the affected area, stating that breast cancer may be caused by intense fondling of the breast, which allows cancer to attack and decompose the breast, causing it to smell; and penis or prostate cancer may be caused by frequent masturbation. This herbalist also said that penis cancer may be caused when gonorrhea medication is improperly 
administered by the patient into the penis opening, and explained that the side effects of this behavior over time can lead to cancer.

Upon our asking, the herbalists expressed interest in participating in long-term case studies involving cooperation with biomedical professionals to confirm diagnoses and patient prognosis over time. There was consensus among participants that a local clinic where herbalists can meet and care for patients would facilitate interdisciplinary collaborations and longitudinal ethnomedicinal research.

\section{Community Service \& Participatory Aspects of Research}

The experiential educational sessions conducted during this research served primarily as a means of cultural knowledge sharing, community capacity building, and reciprocity. For example, a master craftsman taught rural Kormantse residents how to hand-carve locally sourced timber into wave-riding vehicles useful for recreation or enterprise (e.g., surf tourism). Another foreign project leader shared personal experiences of traditional herbal knowledge publication and business. A Ghanaian taxonomist taught Kormantse residents how to harvest and germinate Musanga cecropioides $\mathrm{R}$. Br. ex Tedlie seeds, a native West African timber species. Filming the community service activities served to transfer videography skills to local youth, with an overarching intention of increased outreach potential when the footage is edited for an educational documentary production.

Collegial relationships between foreign researchers and Kormantse leaders, University of Ghana professors, and local botanists facilitated community participation, enabled a locally-driven evolution of long-term goals and research methodology, and encouraged open involvement in data gathering and analyses activities. Kormantse community residents were essential to carrying out this research and played vital roles including interview and informed consent interpretation, participant identification, meeting organization, plant collection, herbarium cabinet construction, data review and local dissemination, background research and writing, voucher curation, photographic journaling, follow-up report writing, interviewing, and documentation. Additional village meetings with participating herbalists were organized by community members after foreign project participants left Ghana. Meeting activities included preliminary results review and discussion, feedback reports, additional plant species collection and documentation, voucher preparation, and community garden installation. ${ }^{10}$

\section{Discussion and Conclusions}

Most of the plants identified in this study are considered native to tropical West Africa and belong to the botanical families Apocynaceae and Fabaceae. These two plant families are distinguished by the bioactive secondary metabolites typically produced by representative species, namely alkaloids (Lin et al. 2011; Michael 2005; Raffauf and Flagler 1960; Wink 2003).

The coastal ecology of the study region may explain the percentage of species with a pan-tropical distribution (approximately 33\%). The long and intense history of trade in Central Region Ghana likely contributed to transatlantic introductions of weedy ${ }^{11}$ plants such as Mimosa pigra L. to tropical American regions of the African Diaspora.

Previously published phytochemical studies on species collected in this research suggest a biological basis for their use in Fante cancer treatments. For example, anti-angiogenic ${ }^{12}$ molecules were isolated from both Voacanga africana Stapf (voacangine) and Boerbavia diffusa L. (punarnavine) (Kim et al. 2011; Saraswati et al. 2013). At least 22 indole alkaloids have been isolated from Rawvolfia vomitoria Afzel., including yohimbine, which has been shown to enhance anticancer drug cytotoxicity in multidrug resistant human cancer cell lines (Beck et al. 1988; Sabri and Court 1978). Flavonoids were found in extracts of Aspilia africana (P. Beauv. ex Pers.) C.D. Adams, Hoslundia opposita Vahl, Mimosa pigra, and Paullinia pinnata L. (Jimoh et al. 2007; Ngadjui et al. 1993; Okwu and Josiah 2006; Yusuf et al. 2003). Also, Dialium guineense Willd. leaf and seed extracts were shown to contain antioxidants (Odukoya and Sofidiya 2007).

Fante Akan herbalists interviewed in this study often associated the manifestation of cancer with "sores." 13 The herbalists demonstrated and described a variety of preparation methods for their ethnobotanical cancer remedies administered orally or topically, with topical remedies cited most often. How Fante cancer ethnomedicine is applied may be a cultural reflection of the disease perception and characterization.

Cancer diagnoses and cures were stated to be largely based on patient observations and feedback, and sometimes confirmed by physicians. Herbalists expressed etiological theories and detailed cancer 
"stage" designations, as well as cancer types and subtypes, suggesting a sophisticated ethnomedicinal treatment of cancer, as understood within the local context.

Breast cancer was the most commonly cited type of cancer treated by the herbalists. This compares to global data (Jemal et al. 2011), as well as the 2012 regional Kumasi cancer registry data (Laryea et al. 2014), which also cite breast cancer as the most common cancer type diagnosed among women, suggesting there may be a similarly high incidence rate among the rural population of Kormantse. The herbalists did not mention either cervical or liver cancer types, even though cervical cancer (in women) and liver cancer (in men) are the two most commonly diagnosed cancers in Ghana (American Cancer Society 2015). Perhaps this finding is simply because the herbalists interviewed in this study did not treat these types of cancer. Alternatively, there could be a discrepancy in Fante herbalist and biomedical diagnostics and/or terminology, or a significant difference in Kormantse cancer incidence rates compared to the country as a whole.

This study was intended to initiate a broader investigation process. Continued recording of local medical terminology, symptom descriptions, and ethno-etiology is significant and critical to our appreciation of how health and wellness is conceptualized, and how disease treatments are applied in a Fante Akan ethnomedicinal context. Research questions need further exploration through additional in-depth interviews, participant observations, and plant collections with herbalists and their patients to identify themes in Fante-Akan traditional medicine, to improve ethnotaxonomic understandings, to better describe how Fante herbal remedies are harvested, prepared, and applied, and to identify any additional species in the Fante Akan cancer ethnopharmacopoeia. Also, more inquiry and observations are required to discern how cancer is wholly defined and identified in Fante Akan ethnomedicine. Anticipated collaborations between herbalists and biomedical professionals (e.g., licensed physicians, registered nurses, and researchers) may help describe patient diagnoses and outcomes, gather population-based cancer incidence data, and determine whether Fante cancer remedies are prescribed for malignancies, growths, abscesses, and/or other illnesses.

Herbalists and other project leaders demonstrated considerable attention to their goal of building a Kormantse research and education center and clinic, where participating herbalists can direct their own studies, ${ }^{14}$ document Fante traditional knowledge, treat and monitor patients with culturally acceptable counseling and care methods, record clinical data (e.g., diagnoses, longitudinal outcomes, etc.), ${ }^{15}$ provide educational opportunities for rural people (e.g., promote participatory research and public discussions regarding how cancers may be acquired in the community and ways to minimize risk, encourage cancer screening for early detection, etc.), and host internationally collaborative academic fora. When herbalists and biomedical physicians are able to make clinical observations ${ }^{16}$ together, symptoms and biological markers used within a Fante Akan ethnomedicinal context to identify and diagnose cancers can be related to and described by conventional biomedical terminology. The stated research objective of the proposed center is to facilitate community-based working relationships between herbalists, biomedical physicians, and scientists in order to bridge crosscultural gaps in medical terminology and perceptions, as well as to encourage integrative medicine approaches to disease treatment and prevention, with an overarching mission to improve Kormantse residents' access to quality affordable and culturally familiar healthcare options.

\section{Acknowledgements}

A set of voucher specimens from this research was deposited in the National Forestry Commission Herbarium in Kumasi Ghana. The authors are extremely grateful to Nana Kwame Akyen II, the Kormantse council of elders, the community of Kormantse, and all of the participants for their research assistance, confidence, and hospitality. We especially want to acknowledge the critical contributions of the participating herbalists, who provided their time, knowledge, and talents during data collection, and also reviewed final drafts of the written manuscript and data tables for accuracy and completeness. We also thank Samuel Otoo, who organized professional meetings and correspondence with herbalists and other project participants during manuscript review. Additionally, we thank University of Ghana Legon professors for supporting this type of research, and assistance with the University of Ghana Noguchi Memorial Institute for Medical Research IRB ethical clearance paperwork submissions for our proposed collaborative longitudinal research. We are also thankful to Ben, our faithful guide, and Cyril our host. We thank the Surfing 
Medicine International Board of Directors, especially President Guy A. Ragosta, without whom Surfing Medicine International would not exist; also Steve Bogle, Elaine Dupont LPN, Chad Durkin, Michael McMahan, Jay Oku, and Marcello Parisi. We are grateful to all Surfing Medicine International mentors, musicians, traditional healers, surfers, sponsors, volunteers, and consultants. Also, Tom Pohaku Stone, Kabuna Kalai of O'ahu, organized and led educational workshops with youth and leaders in Kormantse Ghana to share his expertise and skill in the craft of Native Hawaiian wooden surfboard carving and the healing art of surfing. This was a critical service component of the project and provided the Kormantse community with practical knowledge for sustainable enterprise. Finally, we would like to acknowledge the tax-deductible donations received from individuals in support of this research through Surfing Medicine International, 501 (c)(3), and all the musicians who graciously donated songs for Surfing Medicine International charity album, especially John Butler, as sales from his song 'Ocean' funded the majority of this project.

\section{Declarations}

Permissions: Formal permission to conduct this research was obtained from the Department of Botany, University of Ghana at Legon, the Traditional Chief and council of elders governing the KormantseSalt Pond Cultural Area, and each individual participant.

Sources of Funding: The research was funded through grants, donations, and volunteer effort provided by Surfing Medicine International, 501(c) (3) and associates.

Conflicts of Interest: None declared.

\section{References Cited}

Adanu, R. M. K., J. D. Seffah, R. Duda, R. Darko, A. Hill and J. Anarfi. 2010. Clinical Visits and Cervical Cancer Screening in Accra. Ghana Medical Journal 44:59-63.

African Plant Database. 2012. Conservatoire et Jardin Botaniques \& South African National Biodiversity Institute. Available at: http://www.villege.ch/ musinfo/bd/cjb/africa/details.php? langue $=$ an\&id $=224525$. Accessed on July 27, 2014.

Aikins, A. 2005. Healer Shopping in Africa: New Evidence from Rural-Urban Qualitative Study of
Ghanaian Diabetes Experiences. British Medical Journal 331:737.

Alexiades, M. N. and J. W. Sheldon. 1996. Selected Guidelines for Ethnobotanical Research: A Field Manual. The New York Botanical Garden, Bronx, NY.

American Cancer Society. 2015. Global Cancer Facts and Figures, $3^{\text {rd }}$ edition. American Cancer Society, Atlanta, GA.

Armah, F. A. and E. K. Gyeabour. 2013. Health Risks to Children and Adults Residing in Riverine Environments where Surficial Sediments Contain Metals Generated by Active Gold Mining in Ghana. Toxicology Research 29:69-79.

Asase, A. and G. Oppong-Mensah. 2009. Traditional Antimalarial Phytotherapy Remedies in Herbal Markets in Southern Ghana. Journal of Ethnopharmacology 126:492-499.

Beck, W. T., M. C. Cirtain, C. J. Glover, R. L. Felsted, A. R. Safa. 1988. Effects of Indole Alkaloids on Multidrug Resistance and Labeling of P-glycoprotein by a Photoaffinity Analog of Vinblastine. Biochemical and Biophysical Research Communications 153:959-966.

Berlin, E. A. and B. Berlin. 2005. Some Field Methods in Medical Ethnobiology. Field Methods 17:235-268.

Bernard, H. R. 2006. Research Methods in Anthropology: Qualitative and Quantitative Approaches, $4^{\text {th }}$ edition. AltaMira Press, Oxford, United Kingdom.

Browner, C. H., B. R. Oritz de Montellano, A. R. Rubel, J. Benoist, E. L. Cerroni-Long, J. Charzewska, B. N. Colby, L. C. Garro, N. L. Gonzalez, B. Good, R. L. Hall, J. M. Janzen, A. Kleinman and A. Pollak-Eltz. 2007. A Methodology for Crosscultural Ethnomedicinal Research [and comments and reply]. Current Anthropology 29:681-702.

Busia, K. 2005. Medical Provision in Africa - Past and Present. Phytotherapy Research 19:919-923.

Cunningham, A. B. 1993. African Medicinal Plants Setting Priorities at the Interface between Conservation and Primary Healthcare. People and Plants Working Paper 1. United Nations Educational, Scientific, and Cultural Organization, Paris, France.

Dutfield, G. 2003. Protecting Traditional Knowledge and Folklore: A Review of Progress in Diplomacy and Policy Formulation. International Centre for Trade and 
Sustainable Development (ICTSD) International Environment House, Geneva, Switzerland.

Ebu, N. I., S. C. Mupepi, M. P. Siakwa and C. M. Sampselle. 2015. Knowledge, Practice, and Barriers toward Cervical Cancer Screening in Elmina, Southern Ghana. International Journal of Women's Health 7:31-39.

Etkin, N. L., P. J. Ross and I. Muazzamu. 1999. The Rational Basis of "Irrational" Drug Use: Pharmaceuticals in the Context of Development. In Anthropology in Public Health, Bridging Differences in Culture and Society, edited by R. A. Hahn, pp. 165181. Oxford University Press, New York, NY.

Etkin, N. L. 1988. Ethnopharmacology: Biobehavioral Approaches in the Anthropological Study of Indigenous Medicines. Annual Review of Anthropology 17:23-42.

Hill, Z., C. Kendall, P. Arthur, B. Kirkwood and E. Adjei. 2003. Recognizing Childhood Illnesses and Their Traditional Explanations: Exploring Options for Care-seeking Interventions in the Context of the IMCI Strategy in Rural Ghana. Tropical Medicine \& International Health 8:668-676.

Hutchinson, J. and J. M. Dalziel. 1936. Flora of West Tropical Africa, 2nd edition. Vol. 2. Crown Agents for the Colonies, London, United Kingdom.

Hutchinson, J. and J. M. Dalziel. 1954. Flora of West Tropical Africa, $2^{\text {nd }}$ edition. Vol. 1. Crown Agents for the Oversea Governments and Administrations, London, United Kingdom.

Hutchinson, J. and J. M. Dalziel. 1958. Flora of West Tropical Africa, $2^{\text {nd }}$ edition. Vol. 1. Crown Agents for the Oversea Governments and Administrations, London, United Kingdom.

Hutchinson, J. and J. M. Dalziel. 1963. Flora of West Tropical Africa, $2^{\text {nd }}$ edition. Vol. 2. Crown Agents for the Oversea Governments and Administrations, London, United Kingdom.

Hutchinson, J. and J. M. Dalziel. 1968. Flora of West Tropical Africa, $2^{\text {nd }}$ edition. Vol. 3. Crown Agents for the Oversea Governments and Administrations, London, United Kingdom.

Hutchinson, J. and J. M. Dalziel. 1972. Flora of West Tropical Africa, $2^{\text {nd }}$ edition. Vol. 3. Crown Agents for the Oversea Governments and Administrations, London, United Kingdom.
International Society of Ethnobiology. 2008. International Society of Ethnobiology Code of Ethics. Available at: http://ethnobiology.net/code-ofethics/. Accessed on June 28, 2014.

Jemal, A., F. Bray, M. M. Center, J. Ferlay, E. Ward and D. Forman. 2011. Global Cancer Statistics. CA: Cancer Journal for Clinicians 61:69-90.

Jimoh, F. O., M. O. Sofidiya and A. J. Afolayan. 2007. Antioxidant Properties of the Methanol Extracts from the Leaves of Paullinia pinnata. Journal of Medicinal Food 10:707-711.

Juliá, M. and M. E. Kondrat. 2005. Health Care in the Social Development Context: Indigenous, Participatory and Empowering Approaches. International Social Work 48:537-552.

Kim, Y., H. J. Jung and H. J. Kwon. 2011. A Natural Small Molecule Voacangine Inhibits Angiogenesis both in Vitro and in Vivo. Biochemical and Biophysical Research Communications 417:300-334.

Kleinman, A. 1978. Concepts and a Model for the Comparison of Medical Systems and Cultural Systems. Social Science and Medicine 12:85-91.

Kobetz, E., J. Menard, J. Diem, B. Barton, J. Blanco, L. Pierre, P. Auguste, M. Etienne and C. Brewster. 2009. Community-Based Participatory Research in Little Haiti: Challenges and Lessons Learned. Progress in Community Health Partnerships: Research, Education, and Action 3:133-137.

Laryea, D. O., B. Awuah, Y. A. Amoako, E. OseiBonsu, J. Dogbe, R. Larsen-Reindorf, D. Ansong, K. Yeboah-Awudzi, J. K. Oppong, T. O. Konney, K. O. Boadu, S. B. Nguah, N. A. Titiloye, N. O. Frimpong, F. K. Awittor and I. K. Martin. 2014. Cancer Incidence in Ghana, 2012: Evidence from a Population-based Cancer Registry. BioMed Central Cancer 14:362.

Lewis, W. H. and V. Ramani. 2007. Ethics and Practice in Ethnobiology: Analysis of the International Cooperative Biodiversity Group Project in Peru. In Biodiversity and the Law: Intellectual Property, Biotechnology and Traditional Knowledge, edited by C. R. McManis, pp. 394-410. Earthscan, London, United Kingdom.

Lin, Z., C. Huang, X. Liu and J. Jiang. 2011. In Vitro Anti-tumour Activities of Quinolizidine Alkaloids 
Derived from Sophora Flavescens Ait. Basic \& Clinical Pharmacology \& Toxicology 108:304-309.

McManis, C. R., ed. 2007. Biodiversity and the Law: Intellectual Property, Biotechnology and Traditional Knowledge. Earthscan, London, United Kingdom.

Michael, J. P. 2005. Indolizidine and Quinolizidine Alkaloids. Natural Products Report 22:603-626.

Ndukwu, B. C. and N. B. Ben-Nwadibia. 2005. Ethnomedicinal Aspects of Plants Used as Spices and Condiments in the Niger Delta Area of Nigeria. Ethnobotanical Leaflets. Available at http:// www.ethnoleaflets.com/leaflets/niger.htm. Accessed on July 2, 2015.

Ngadjui, B. T., J. F. Ayafor, B. L. Sondengam, J. D. Connolly, D. S. Rycroft and F. Tillequin. 1993. Oppositin and 5-O-methylhoslundin, Pyronesubstituted Flavonoids of Hoslundia opposita. Phytochemistry 32:1313-1315.

Odukoya, O. A. and M. O. Sofidiya. 2007. Free Radical Scavenging Activity of Some Anticancer Herbs. Planta Medica 73:895.

Okwu, D. E. and C. Josiah. Evaluation of the Chemical Composition of Two Nigerian Medicinal Plants. 2006. African Journal of Biotechnology 5:357-361.

Raffauf, R. F. and M. B. Flagler. 1960. Alkaloids of the Apocynaceae. Economic Botany 14(1):37-55.

Ragosta, S. 2011. Historical Influences on Jamaican Maroon Ethnomedicine: A Comparative Study of West African and Jamaican Maroon Ethnopharmacopoeia. Doctoral Dissertation, Botany Department, University of Hawai'i, Honolulu, HI.

Sabri, N. N. and W. E. Court. 1978. Stem Alkaloids of Rauwolfia vomitoria. Phytochemistry 17:2023-2026.

Saraswati, S., A. A. Alhaider and S. S. Agrawal. 2013. Punarnavine, an Alkaloid from Boerhaavia diffusa Exhibits Anti-angiogenic Activity via Downregulation of VEGF in Vitro and in Vivo. ChemicoBiological Interactions 206:204-213.

The Plant List. 2013. Version 1.1. Available at: http://www.theplantlist.org/. Accessed on June 30, 2014.

Raffauf, R. F. and M. B. Flagler. 1960. Alkaloids of the Apocynaceae. Economic Botany 14:37-55.

Sackey. E. K. A. and O. M. J. Kasilo. 2010. Intellectual Property Approaches to the Protection of
Traditional Knowledge in the African Region. African Health Monitor 13:89-102.

Tongco L. 2007. Purposive Sampling as a Tool for Informant Selection. Ethnobotany Research and Applications 5:147-158.

Missouri Botanical Garden. 2014. Tropicos Database. Available at: http:/ /www.tropicos.org/

Name/13018667. Accessed on June 30, 2014.

Vandebroek, I. 2013. Intercultural Health and Ethnobotany: How to Improve Healthcare for Underserved and Minority Communities? Journal of Ethnopharmacology 148:746-754.

Wink, M. 2003. Evolution of Secondary Metabolites from an Ecological and Molecular Phylogenetic Perspective. Phytochemistry 64:3-19.

Yusuf, U. K., N. Abdullah, B. Bakar, K. Itam, F. Abdullah and M. A. Sukari. 2003. Flavonoid Glycosides in the Leaves of Mimosa Species. Biochemical Systematics and Ecology 31:443-445.

\section{Biosketches}

Summer Ragosta resides in California where she cares for her family, teaches, conducts ethnobotany research, and leads charity development projects.

Ivelyn Harris resides in Rio Grande Valley Jamaica, practices Traditional Maroon Herbal Medicine, and wrote the book Healing Herbs of Jamaica.

Alex Asase resides in Accra Ghana and spends time teaching and researching traditional West African uses of plants for medicine.

\section{Notes}

${ }^{1}$ Environmental toxicology studies in Ghana indicate that mining activities are associated with increased levels of toxic pollutants, such as heavy metals, in ambient soil and water, posing an increased cancer risk to surrounding communities (Armah and Gyeabour 2013).

${ }^{2}$ Vaccine preventable cancers such as liver cancer associated with Hepatitis B and cervical cancers caused by HPV (primarily types 16 and 18), are relatively high in Ghana compared to more developed areas of the world (Jemal et al. 2011).

3"Traditional" implies Fante cultural knowledge that has been known and transferred inter-generationally over time.

${ }^{4}$ Specifically, we hope this documentation prevents 
unethical bioprospecting developments that do not include equitable indigenous profit-sharing (McManis 2007).

${ }^{5}$ During the first author's doctoral dissertation research, observations and community contacts were made during an initial visit to Ghana from June 1 to 21, 2005; Ragosta resided in the coastal village of Biwiri, adjacent to the village of Kormantse, as an invited guest of Nana Kwame Akyen II and Nana Bonku V.

'Before international project leaders arrived in Ghana (July 2013), the traditional leader of Kormantse (Nana Kwame Akyen II) was contacted and asked to introduce the researchers to herbalists in his community who use plants to treat cancer.

${ }^{7}$ Some herbalists were interviewed only once, either at the research meeting area, or at their place of practice.

${ }^{8}$ The foreign project team consisted of two ethnobotanists (Ivelyn Harris \& Summer Ragosta), one Native Hawaiian master wood carver (Tom Pohaku Stone, III), and one watershed scientist and film producer (Guy A. Ragosta). The Ghanaian research team consisted of one botanist from Accra (Alex Asase), one ethnotaxonomist from Kumasi (Ntim Gyakari), and several Kormantse community members including Nana Kwame Akyen, II, Emmanuel Otoo, Isaac Dadzie, Amos Anane, Timothy Bentum, Samuel Otoo, and Nana Weehi. Educational sessions occurred concurrently with ethnobotanical research (i.e., some team members led surfboard carving sessions and videography lessons in the community, while other team members were interviewing herbalists and collecting plants). The ethnobotanical research components (interviews, plant collections, etc.) allowed for direct participation, training, and knowledge sharing opportunities with local residents. Daily research and education activities lasted typically six to seven hours daily, and were usually followed by one to three hours of evening activities carried out with project participants and other community members (e.g., plant pressings, species identification/ taxonomy lessons, seed germination, and other educational discussions). After foreign project team members left, training of the herbarium curator continued remotely via communications over email, phone, and text, as well as locally with assistance from N. Gyakari, a Ghanaian taxonomist and technical herbalist. Locally driven data collection and documentation also continued during subsequent meetings and plant collections with participating herbalists.
${ }^{9}$ Maintaining secrecy of proprietary information such as formulations and preparation/application methods associated with medicinal species protects herbalists' business interests; therefore, plant species names are not included in Table 2.

${ }^{10}$ During interviews the need or desire for a medicinal plant garden repository was expressed. Garden species were selected, collected, and planted by the herbalists; also native timber species were planted and cared for by community members.

11Plants described as weedy are usually hardy and have several defining characteristics, such as profuse seeds and the ability to establish readily in disturbed places.

${ }^{12}$ Angiogenesis is the process of new blood vessel formation and is associated with cancerous tumor growth and spread (see http://www.cancer.gov/ cancertopics/factsheet/Therapy/angiogenesis inhibitors for more information).

${ }^{13}$ It is unclear from the West African ethnobotanical literature whether the term cancer has been previously documented as a disease associated with the presence, or defined by the presence, of sores. However, one study in the Niger Delta area of Nigeria recorded several uses of Xylopia aethiopica (Dunal) A. Rich, including "as a dressing for sores and rubbed onto gums for pyorrhea and in the local treatment of cancer" (Ndukwu and Ben-Nwadibia 2005).

${ }^{14}$ It is expected that the proposed community-based herbal research and education clinic will support traditional herbal practitioners in their own research and documentation interests and goals by providing a local collaborative space. Research participants will be asked to sign memorandums of understanding stating that all studies and projects conducted at the clinic will conform to International Society of Ethnobiology (2006) Code of Ethics (with 2008 additions). Although drug discovery is not the intended focus of the proposed clinic, if participating herbalists initiate interest in benchtop bioassays or other phytochemical testing or development of their traditional botanical remedy that could result in a value-added product or other form of financial gain, we will encourage appropriate use of guidelines for intellectual property (IP) protection enacted in previously successful models (e.g., International Cooperative Biodiversity Group-Peru Project (Lewis and Ramani 2007), such as confidentiality and contractual agreements ensuring equitable community benefit sharing, and enlist advice from IP attorney(s) in prior informed consent documents and discussions in order to make partici- 
pants aware of current local and global IP and patent laws.

${ }^{15}$ The research intention of the clinic is to facilitate participatory and collaborative, non-experimental longitudinal observational monitoring of patients currently receiving botanical remedies for cancer, with assistance from bio-medical personnel and in compliance with institutional review board ethical guidelines for human subjects research. We expect the results will improve participating health care providers' practices and public welfare by supporting health education programs and encouraging integrated health care practices that are culturally familiar, affordable, and based on clinical safety and efficacy data.

${ }^{16}$ Case studies involving interviews and surveys with patients and health care providers, results, and interpretations of blood-work and physical exams may facilitate documentation of patient outcomes over time and relate Fante ethnomedicinal terms to biomedical taxonomy for cross-cultural comparability. 